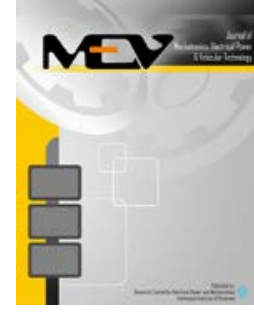

Journal of Mechatronics, Electrical Power, and Vehicular Technology

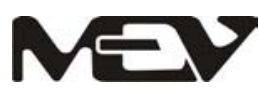

\title{
An alternative design and implementation of a solid state on-load tap changer
}

\author{
Benjamin Kommey $^{\mathrm{a}, *}$, Elvis Tamakloe ${ }^{\mathrm{b}}$, Gideon Adom-Bamfi ${ }^{\mathrm{b}}$, Daniel Opoku ${ }^{\mathrm{b}}$ \\ ${ }^{a}$ Kwame Nkrumah University of Science and Technology \\ PMB KNUST- COE, Kumasi, Ghana \\ ${ }^{b}$ Kwame Nkrumah University of Science and Technology \\ PMB KNUST- EE, Kumasi, Ghana
}

Received 5 September 2021; Accepted 19 November 2021; Published online 31 December 2021

\begin{abstract}
Power quality and reliability are of great importance in the modern world, whether it be the power generated by the power utilities or the power consumed by the customer respectively. They need these supplies to be at its optimum value so that the cost is effective, and the safety of devices assured otherwise problems such as overvoltage, under-voltage, and voltage sags caused by disturbances in the power supply could be disastrous. On-load tap changers (OLTC) have therefore been used since the inception of electrical engineering. The main function of the OLTC is to change the turns of the transformer winding so that the voltage variations are limited without interrupting the secondary current. The major idea is that the electronic switches and other smart systems provide more controllability during the tap changing process, unlike mechanical switches. This paper presents an alternative design and implementation of a low-cost solid-state OLTC and employs a control strategy that is microcontroller-based, ensuring the desired flexibility and controllability required in programming the control algorithms. It eliminates the limitations of both mechanical and hybrid OLTCs (arcing, slow response time, losses) and is userfriendly (provides an effective communication medium). Voltage regulation is achieved by varying the turns of the transformer winding whiles it is energized, supplying load current and with the tap selection carried out on the primary side. Therefore, this approach provides a less expensive system but ensures the efficiency and reliability of voltage regulation.
\end{abstract}

(C2021 Research Centre for Electrical Power and Mechatronics - Indonesian Institute of Sciences. This is an open access article under the CC BY-NC-SA license (https://creativecommons.org/licenses/by-nc-sa/4.0/).

Keywords: on-load tap changer; solid-state switch; potential transformer winding; voltage regulation.

\section{Introduction}

The role of the power utility is not just limited to providing power supply to the customer but also to ensuring good quality and reliability with minimum disruptions in terms of overvoltage, under-voltage, imbalance, noise, and harmonics [1]. These disturbances are undesirable to most industrial and commercial end-users since they have dire economic implications. Voltage regulators, capacitors, and dc stored energy systems amongst others have been employed to rectify these problems. The most popular agent for controlling voltage levels at the distribution and transmission systems is the on-load tap changer transformer. The OLTC has therefore been widely used since the introduction of electrical energy [2]. Tap changers are generally divided into three categories depending on their method of

\footnotetext{
${ }^{*}$ Corresponding Author. Tel: +233-5077-03286

E-mail address: bkommey.coe@knust.edu.gh
}

operation; off circuit tap changer, offload tap changer and on-load tap changer [3]. The latter is preferable as there is no disconnection of the transformer when changing the tap setting, thus the operation of supplying the load demand remains uninterrupted. Several on-load tap changing systems exist. Among these are mechanical, electronically assisted (hybrid), and fully electronic (solid-state) types. The mechanical and electronically assisted types have considerable drawbacks such as arcing, high maintenance, service cost, and slow response time [4]. Hence, system reliability is reduced.

However, to eliminate these shortcomings, alternative configurations have been introduced which improve the reliability of the system. To date, the proposed constructions have been able to eliminate arc formation using a tap changer where quick operation is desirable. In such a case, the fully electronic (solid-state) tap changer provides the flexibility, controllability, and reliability desired. 
On-load tap changing involves techniques to sense voltage variations and relay this information to an appropriate device for decisions to be taken. The essential nature of the information obtained from this activity has prompted a few studies aimed at developing systems for solid-state on-load tap changing with a handful of prototypes developed. Some of these solid states on-load tap changing systems have been developed for use in medium voltage (MV) systems, [5][6]. Similarly, in [7][8], solid state OLTCs are used to mitigate MV system losses. In [9][10], also employ solid state devices in low voltage (LV) distribution systems for on-load tap changing. In [11][12], a microcontroller is utilized for control operations. OLTCs lessen voltage sags in LV systems with power semiconductor devices [13][14].

A. K. Gamit showcases a design that maintains the desired load voltage irrespective of input voltage variations [15]. This system has thyristor switched taps on the high voltage (HV) side of the transformer and the load on the low voltage (LV) side. Load voltage variations are sensed by the microcontroller and the value compared with a reference. This gives the command to trigger the appropriate antiparallel thyristor for the needed tap selection.

Rao et al. and Thakare et al. present a system that regulates voltage using static OLTC with sequential controllers [16][17]. This model has GTO switched taps on the primary side and a load connected to the secondary side of a transformer. The load voltage was measured, compared with the pre-set value and an error value obtained. Error values found outside the dead band gave a lower or higher correction after a pre-determined delay else no operative action was taken. This process continued until the load voltage was within the inner dead band. The delay in tap selection as a result of this process makes it less reliable.
A work conducted by [18] employed the use of thyristors for tap changing. The thyristors tap changer system used two antiparallel thyristors for each tap in a single phase operation. Voltage selection was achieved when one group of antiparallel thyristors were turned on and the others off. Transitioning from one tap to the other downwards was problematic as a short circuit could occur and damage the system in case of a wrong switching sequence which renders the system inefficient. Additionally, the thyristor/GTO model which resolved the switching problem needed extra circuitry which resulted in high costs.

Kavad et al. and Pota et al. model offer a system that has a microcontroller that controls the tap selection on the secondary side of the transformer based on the transformer output voltage [19][20]. The tap changing on the secondary side of the transformer leaves the system vulnerable to arcing since tap selection at the secondary side produces high current resulting in sparks which slightly increases cost [21][22].

\section{Materials and Methods}

\section{A. Proposed system design and architecture}

The presented solid state on-load tap changer consists of three primary and two secondary units as represented in Figure 1. These are the transformer unit (TU), switching unit (SU), the microcontroller system communication unit (MSCU), the display unit (DU) and the signal sensing, conversion and rectification unit (SSCRU).

The SU which employs solid state static switches were connected to the control unit of the microcontroller and to the taps on the primary side of the transformer as illustrated. Potential

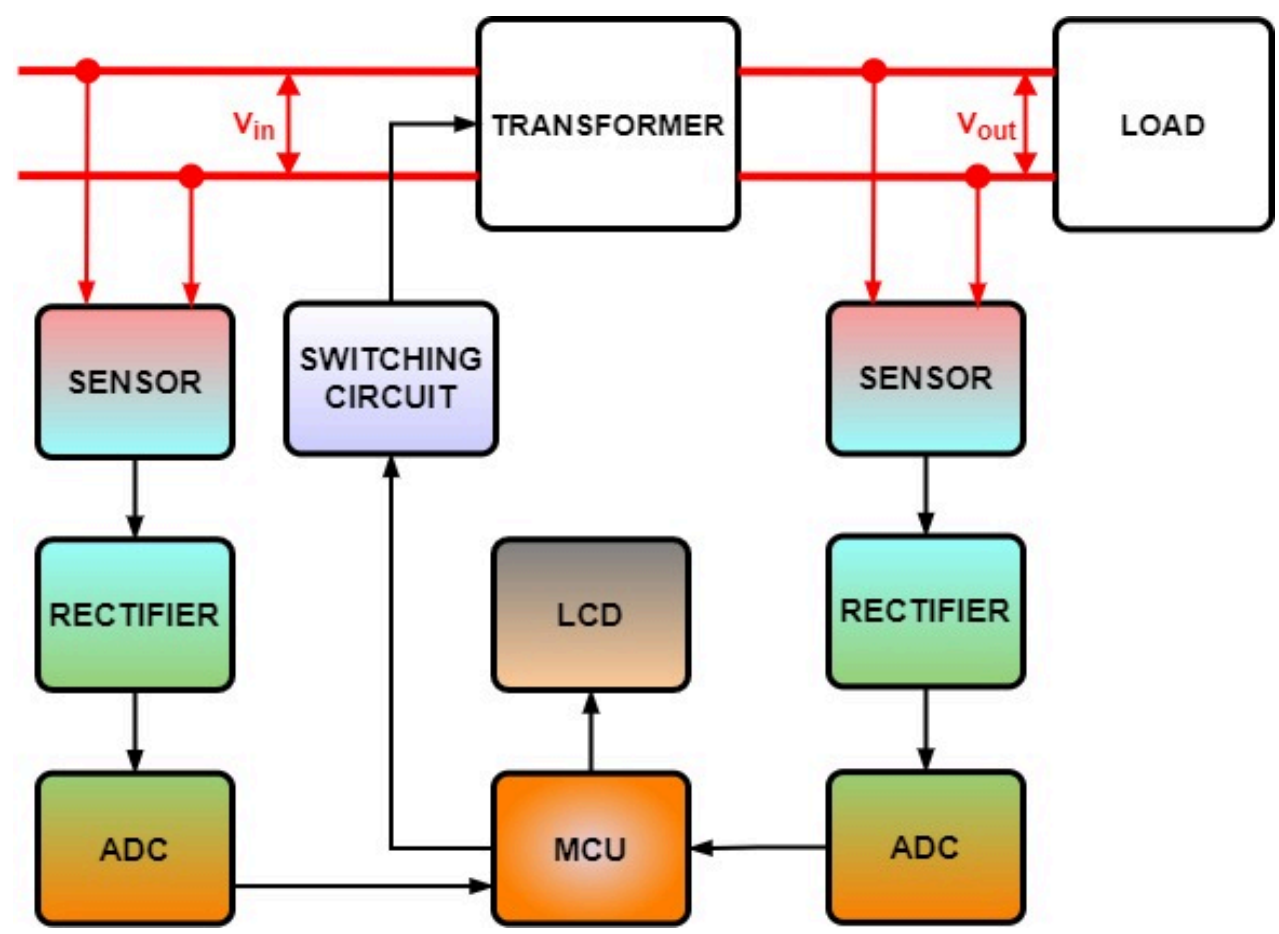

Figure 1. Block diagram of proposed system architecture 
transformers and rectifiers were used as sensors to step down voltages from the input and output of the main transformer which were fed to the ADC of the microcontroller simultaneously. The microcontroller is responsible for converting the analog signals into digital values for processing. The DU which was interfaced with the microcontroller projected numerically the input and load voltages as well as the voltage drops. The SU, ADC, LCD and the microcontroller were powered by an independent or auxiliary power supply.

\section{1) The transformer unit (TU)}

The transformer operates on the law of electromagnetic induction (EMI). The EMI is defined as the production of an electromotive force (EMF) across an electrical conductor in a changing magnetic field. The conductors used in transformer cores are wound several times. Several connections brought outside from any points between the terminals of the transformer winding with appropriate distancing were transformer tapings. These taps are principally used for voltage control mechanisms and were located on either side of the transformer. Based on the transformer EMF equation given by.

$$
\frac{E_{2}}{E_{1}}=\frac{N_{2}}{N_{1}}=K
$$

where $E_{2}$ and $E_{1}$ are the secondary and primary voltages, $N_{2}$ and $N_{1}$ the secondary and primary turns respectively and $K$ the turns ratio.

From equation (1), it is observed that varying the number of turns affects the desired voltage. Therefore, to maintain a constant secondary voltage irrespective of the primary voltage, the primary turns were varied to change the turns ratio. This was the tap-changing concept. The KNUST laboratory's single-phase transformer with five taps was used as the TU.

\section{2) The switching unit (SU)}

The SU uses static solid-state power switches. The choice of switch, working principles, and position on the transformer were factors considered in the design process to achieve efficiency at a minimal cost. There are several static switches employed in AC switching. However, the choice of switch used in the implementation of this project was a triac with a zero-crossing optically isolator or triac driver. The factors that accounted for the choice were the cost, response time, forward voltage drop, losses, the durability of the switch, and the operation voltage of the transformer. The triacs were attached to heat sinks or dissipating brackets to ensure safety when driving the load. The triac driver or optoisolator employed in this system adds a desirable feature of isolation and protection. It interfaces between the microcontroller and triacs to control resistive and inductive loads in $A C$ operation. The pictorial and circuit view of the triac driver or coupler is shown in Figure 2.

As depicted in Figure 2, the triac driver houses an LED, optically triggered triac, zero-crossing detector,

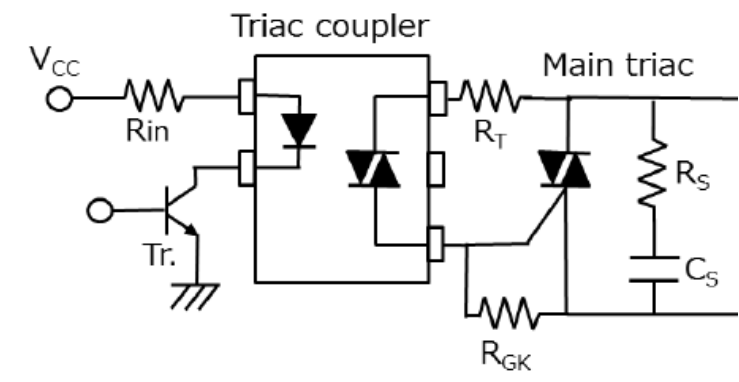

Figure 2. Pictorial and circuit view of the triac driver or optoisolator [23]

and a snubber capacitor. A high signal received at a pin glows the LED which then triggers the internal triac. The internal triac subsequently receives a gate pulse and connects it to the $240 \mathrm{~V}$ end. The zerocrossing provided was primarily to drive resistive loads to ensure minimal switching losses and interferences injected into the supply. The snubber circuit having the resistor $\left(R_{\mathrm{S}}\right)$ and capacitor $\left(C_{\mathrm{S}}\right)$ was attached to suppress reverse voltage and control the rate of rising at the turn-off to prevent $d v / d t$ retriggering when operating inductive loads. The additional benefit was to reduce radiated noise.

Current flows through the snubber circuit in the event of a sudden voltage spike $d v / d t$. The snubber capacitor $C_{S}$ suppresses $d v / d t$ while $R_{\mathrm{S}}$ prevents device failure due to discharge current from $C_{S}$ when the triac switches on. A $40 \Omega$ maximum resistance and $0.01 \mu \mathrm{F} C_{S}$ were generally considered for $100 \mathrm{~V}$ AC power. The charging time $(T)$ of the snubber capacitor is given by the expression [23]:

$$
T=C_{S} \times\left(R_{L}+R_{S}\right)
$$

where $R_{\mathrm{L}}$ is the load resistance.

\section{3) Microcontroller system communication unit (MSCU)}

The MSCU uses a microcontroller interfaced with an LCD to ensure quality and effective communication. The microcontroller was used as the logical central process control unit to process the input signals and produce a suitable output signal according to the program loaded onto it. It has ADC's which are used for converting rectified analog input and output voltages. These voltages are received as high signals by the microcontroller through its ADC pins where they are converted to digital values. Based on the program loaded on the microcontroller, decisions are made as to which tap must be selected on the transformer to ensure constant load voltage supply. Since the SU was directly connected to the high voltage side of the transformer [24], we can protect the microcontroller from exposure to high voltages with triac drivers or opto-isolator [25].

The LCD which is essentially the output device was used to showcase the decisions made by the microcontroller in text and numerical format. It shows the input and output voltages recorded, the tap selected, and the system's voltage drops. This was needed to provide easy data collection. Accurate data transmission to the display is ensured due to the wired connection employed in the system communicating with the microcontroller. 


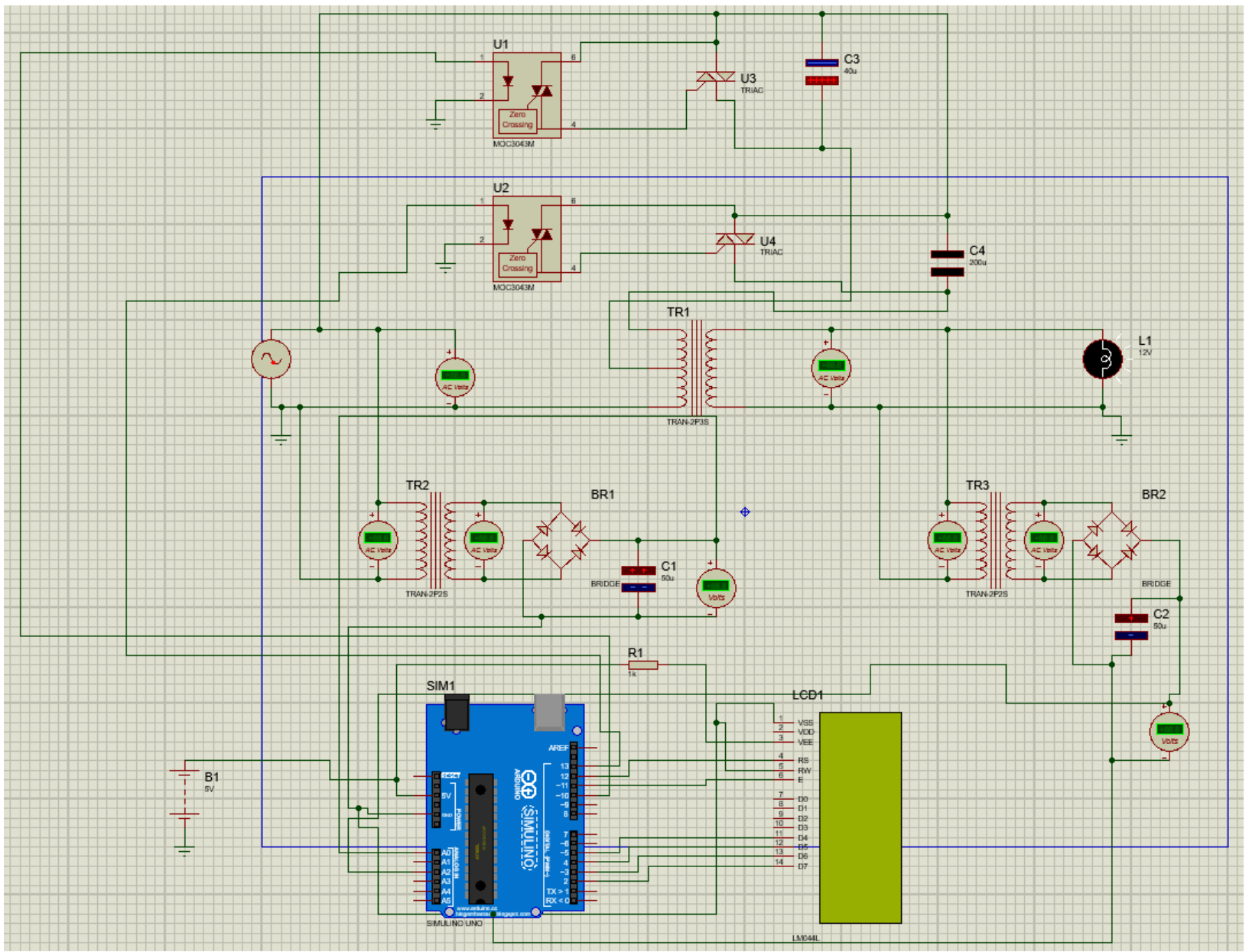

Figure 3. Circuit diagram with all components

\section{B. Circuit illustration and flow chart}

The presented solid-state on-load tap changer components in Figure 1 were illustrated in circuit form using Proteus professional design and simulation tool. Represented in the circuit in Figure 3 are the transformer unit (TU), control unit $(\mathrm{CU})$, switching unit (SU), display unit (DU) and the auxiliary power supply. The transformer unit (TR1) that was used for the simulation had only two taps whose terminals were connected to the triacs. This subsequently reveals the number of triacs (U3, U4) and triac drivers or opto-isolators (U1, U2) that were employed in the switching process. The transformers (TR2, TR3) were involved to step down the input and output alternating current $(A C)$ voltages for the microcontroller action. Bridge rectifiers (BR1, BR2) and capacitors $(\mathrm{C} 1, \mathrm{C} 2)$ were used to convert ac to dc and to smoothen the dc respectively. The auxiliary power supply source (B1) provides the dc needed to power the microcontroller and display. The microcontroller (SIM1) receives the analog input and load voltages through the analog pins, convert the values into digital forms using the ADC and produces a suitable output signal based on the loaded program. A pulse is then authorized to the selected triac through the triac drivers for appropriate tap selection.
In Figure 4 is a view of the flow chart showing the schemes of operation of the solid-state on-load tap changer. It begins with the initialization of the program as well as the display. Any voltage sampled between $15-20 \mathrm{~V}$ results in the selection of Tap 1 to ensure a constant output voltage else the microcontroller continues to sample voltages between 21-39 V, 40-57 V, and 58-65 V where other corresponding Tap may be selected. This cycle continues until an appropriate Tap is selected. Sampled voltages above $65 \mathrm{~V}$ result in a break to this program cycle.

\section{Results and Discussions}

A prototype of the single-phase solid state onload tap changer comprising of the transformer, switching, microcontroller, and display unit was set up in the KNUST laboratory. The prototype was subjected to testing in a laboratory environment to achieve precise simulation of the real-life setting. Figure 5 shows the prototype test setup.

The primary of the transformer was connected to a $240 \mathrm{~V}$ rms input voltage and with the aid of a variac, various voltage variations were achieved. The triacs connected to the corresponding taps were triggered by a high signal from the microcontroller to select a particular tap based on the program or algorithm loaded under different voltage situations. 


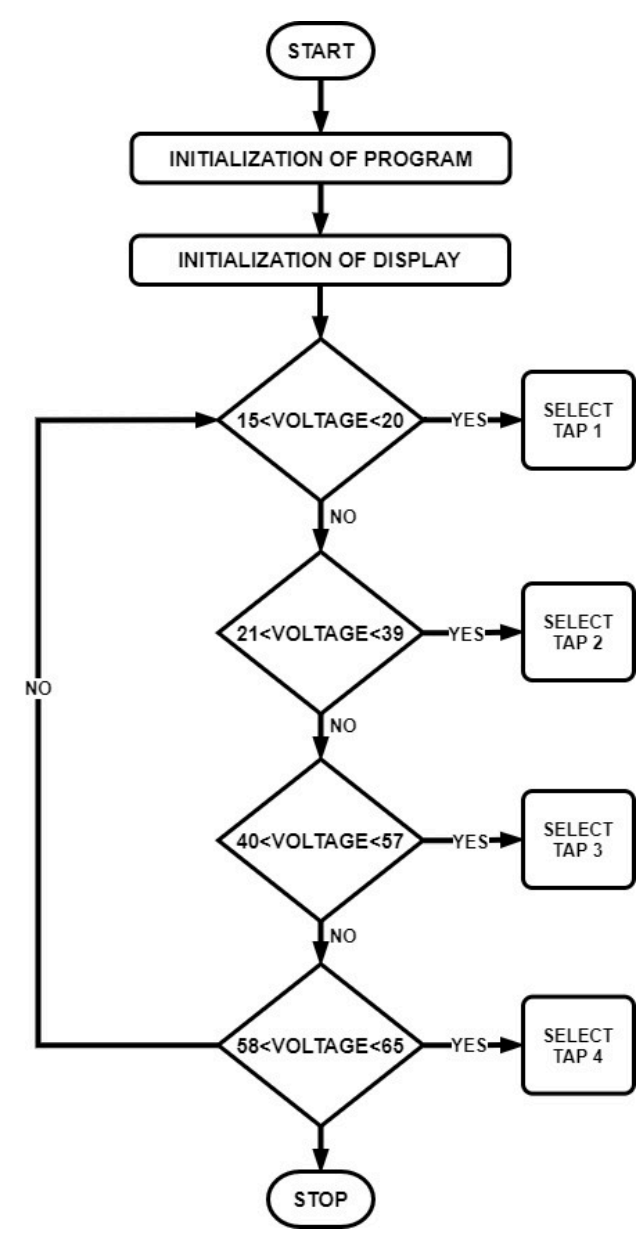

Figure 4. Interaction of forces in the APF

The circuit was tested with a 2 kVA power transformer having four taps; Taps 1, 2, 3, and 4. Four tests were run on the circuit to determine proof of concept and performance. In these tests, the input and output voltages of the power transformer were manually measured with a voltmeter and compared

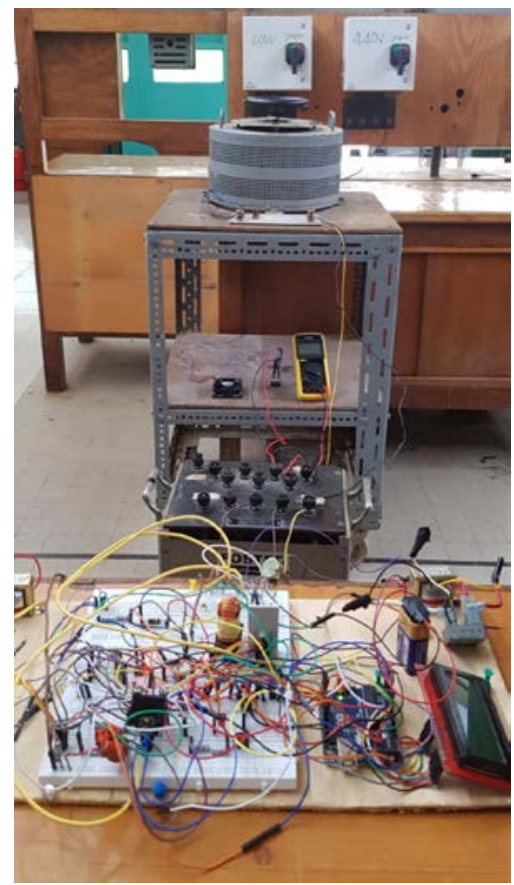

Figure 5. Test setup of prototype
Table 1.

Input voltages with corresponding selected taps and nominal load voltage values

\begin{tabular}{llll}
\hline Condition & Input voltage & Output voltage & Tap number \\
\hline Nominal & $15 \mathrm{~V}-20 \mathrm{~V}$ & $5 \mathrm{~V}$ & Tap 1 \\
& $21 \mathrm{~V}-39 \mathrm{~V}$ & $5 \mathrm{~V}$ & Tap 2 \\
& $40 \mathrm{~V}-57 \mathrm{~V}$ & $5 \mathrm{~V}$ & Tap 3 \\
& $58 \mathrm{~V}-65 \mathrm{~V}$ & $5 \mathrm{~V}$ & Tap 4 \\
\hline
\end{tabular}

with the displayed voltages from the microcontroller. A nominal voltage of $5 \mathrm{~V}$ with a tolerance of $\pm 1.5 \mathrm{~V}$ was expected to drive the motor load connected across the secondary side of the transformer. At this condition Tap 1 was active or on. The results of the tests are summarized in Table 1.

The prototype was tested for reliability by measuring the output or load voltage of the transformer when the input voltage was increased steadily. From the table, as the input voltage increased above the nominal, the microcontroller generated a pulse which increased the tap setting by one (changing from Tap 1 to Tap 2) to maintain the load voltage at nominal value. The microcontroller continued to monitor the input voltage and once it fell within the desired range, the appropriate tap was selected, and the cycle continued to loop. The microcontroller managed to maintain the load at its nominal voltage within its specified value of $5 \pm 1.5 \mathrm{~V}$ and it was shown to be reliable. Figure 6 and Figure 7 show pictures of the OLTC prototype setup.

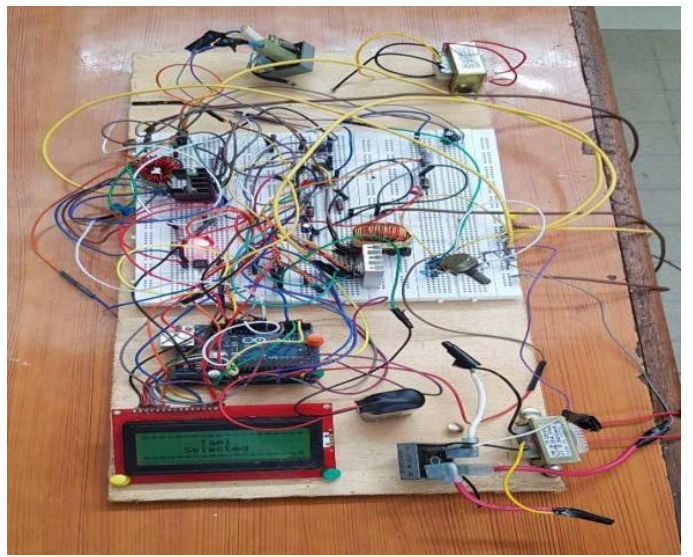

Figure 6. A view of the setup showing Tap 1 selected on LCD display with an LED glow indicator

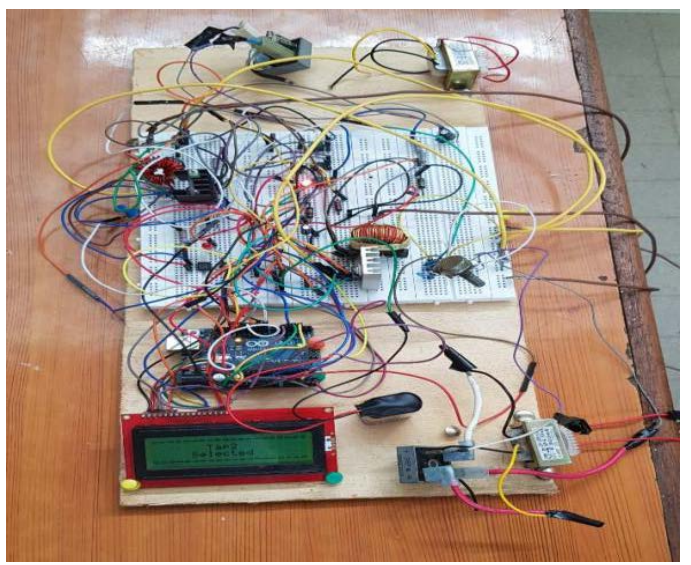

Figure 7. Another view of the setup indicating Tap 2 selected with a corresponding LED glow 
An additional system test was conducted which involved higher voltage ranges above $100 \mathrm{~V}$. After the test, two triacs which controlled Taps 3 and 4 were damaged. This was attributed to protection related issues.

\section{Conclusion}

In this paper, we have proposed and tested a system for on-load tap changing on single phase power transformers. Based on theoretical and empirical results, the system maintained a nominal load voltage despite input voltage variations. This proves that the solid-state on-load tap changer differentiates between transformer taps. Therefore, this system is a viable option for on-load tap changing. Compared to other on-load tap changing systems, it is more effective, accurate, and costeffective. The control and switching system employed in this system eliminates arcing, contact wear since there are no movable parts, reduces maintenance cost, improves switching time, system safety, and stability. The designed system was highly practical and adaptable for LV installations. It can be used to maintain voltage levels in an electrical system given the needed system protection.

\section{Acknowledgment}

We thank the Faculty of Electrical and Computer Engineering, College of Engineering, KNUST for allowing us to use their laboratories for the experiments.

\section{Declarations}

\section{Author contribution}

All authors contributed equally as the main contributor to this study.

\section{Funding statement}

This research did not receive any specific grant from funding agencies in the public, commercial, or not-forprofit sectors.

\section{Conflict of interest}

The authors declare no known conflict of financial interest or personal relationships that could have appeared to influence the work reported in this paper.

\section{Additional information}

Reprints and permission information is available at https://mev.lipi.go.id/.

Publisher's Note: Research Centre for Electrical Power and Mechatronics - Indonesian Institute of Sciences remains neutral with regard to jurisdictional claims and institutional affiliations.

\section{References}

1] S. M. Bashi, "Microcontroller-based fast on-load semiconductor tap changer for small power transformer," Journal of Applied Sciences. 5(6): pp. 999-1003, 2005.

[2] P. Okanik, B. Kurth and J. H. Harlow, "An update on the paralleling of OLTC power transformers," IEEE Transmission and Distribution Conference, vol. 2, pp. 871-875. 1999.
[3] C.R. Bayliss, Transmission and Distribution: Electrical Engineering, $2^{\text {nd }}$ ed. Newnes, 1999.

[4] R. Shuttleworth, A. J. Power, X. Tian, H. Jiang and B. A. T. Al Zahaei, "A novel thyristor-assisted tap changer scheme," 14th International Conference and Exhibition on Electricity Distribution. Part 1. Contributions (IEE Conf. Publ. No. 438), pp. 28/1-28/5 vol.1, 1997.

[5] Hao Jiang, R. Shuttleworth, B. A. T. Al Zahawi, X. Tian and A Power," Fast response GTO assisted novel tap changer," IEEE Transactions on Power Delivery, vol. 16, no. 1, pp. 111-115, Jan. 2001.

[6] G. H. Cooke and K. T. Williams, "New thyristor assisted diverter switch for on-load transformer tap changers." IEE Proceedings- $B$, 139: 507-511, 1992.

[7] R. Fourie and H. du T. Mouton, "Development of a MV IGBT based solid-state tap changer." IEEE, AFRICON, 2009.

[8] R. Sangeerthana and S. Priyadharsini, "Controlling of power transformer tap positions using facts devices." Perspective in Communication," Embedded-Systems and Signal Processing International Journal, Vol. 4, Issue 7, 2020.

[9] D. Nadeem, Haroon-ur-Rashid and M. Saeed, "Fully electronic tap changer control," 2013 IEEE Conference on Clean Energy and Technology (CEAT), 2013, pp. 114-117.

[10] T. Yuvaraja and S. Vigneshwaran, "Voltage regulation by solid state tap change mechanism for Distributing Transformer," International Journal of Engineering Research and Technology, Vol.4, Issue 02, 2015

[11] V. S. Kale, H. K. Chaure, and P. J. Pawar, "On Load Tap Change of Transformer using Microcontroller." International Journal for Scientific Research and Development, Vol.6, Issue 01, 2018.

[12] H. R. Sawake, B. V. Sande, V. A. Ekkaldevi, S. R. Argade, and N. P. Zinjad, "Power electronic based on-load tap changer," International Journal of Research in Engineering, Science and Management, Vol.1. Issue 12, 2018.

[13] A. Ahmed, N. Ullah, and M. Idrees, "Design and simulation of imporved on load tap changer to mitigate voltage sag/swell," International Journal of Power Systems, Vol. 5, 2020.

[14] P. P. Adasur and D. G. Chougule, "A review of power transformer tap switching using semiconductor devices," International Journal of Research Publications in Engineering and Technology, Vol. 2, Issue7, 2016.

[15] A. K. Gamit. "Design of solid-state on-load tap changer for transformer using microcontroller," International Journal of Science and Research, Vol.7, Issue 11, 2018

[16] Rao, S. V. M. Bhuvanaika, B. Subramanyeswar, "Fine voltage control using oltc by static tap change mechanism," International Journal of Advanced Computer Research; Bhopal Vol. 2, Iss. 4, (Dec 2012): 328-333.

[17] P. B. Thakare, and M. A. Mechkul, "Electronics solid state voltage regulating relay for on load tap changer distribution transformer for automatic voltage regulation," International Journal of Modern Trends in Engineering and Research, Vol.4, Issue 06, 2017

[18] M. H. Taha, "On load single-phase solid-state tap changer," International Journal of Engineering Technologies, Vol.2, No.2, 2016.

[19] A. B. Kavad, S. N. Khandhar, B. A. Sodha, and Y.D. Tita, "Solid state tap changer for utility transformer," International Journal for Scientific Research and Development, Vol.5, Issue 02, 2017.

[20] I. K. Pota, S. Bhatti, I. Rathod, P. Sudiya, and S. Rohit, "Microcontroller based tap changer for power transformer," Journal of Emerging Technologies and Innovative Research, Vol.5, Issue 04, 2018

[21] M. A. Sanjay, T. S. Raosaheb, N. S. Ravindra, V. R. Kirandas, "Solid state on load tap changer for transformer," Resincap Journal of Science and Engineering, Vol.5, Issue 04, 2021.

[22] N. Nagalakshmi and T. Thivagar, "Automatic tap-changer with triac switch for constant voltage and current measurements," International Journal of Recent Technology and Engineering, Vol. 9, Issue 2, 2020

[23] "Triac couplers - basic properties and application design," TOSHIBA electronic devices and storage corporation, Rev.1.0 2018

[24] V. T. Chacko, M. P. Noufal, N. P. Mohan, S. B. Vinod and K. A. Eldhose, "Solid state on load tap changer for transformer using arduino," International Research Journal of Engineering and Technology, vol. 4, no. 4, p. 4, 2017

[25] V. S. Bugade, E. Mishra, M. H. Jayebhaye, H. Joshi, A. Patil, and B. Kale, "Automatic voltage control of load using on load tap changer," International Journal for Research in Applied Science and Engineering Technology, Vol. 6, Issue 03, 2018. 